để xâm nhập và ly giải tế bào ung thư nguyên bào thần kinh và thử nghiệm lâm sàng với đối tượng là tế bào ung thư đầu cổ. Các thử nghiệm đều cho thấy khả năng ức chế và gây chết tế bào ung thư của MeV nhắm muc tiêu EGFR trên cả in vitro và trên mô hình chuột thiếu hụt miễn dịch mang các khối ung thư người nói trên (in vivo).

Từ những cơ sở lý luận và thực tiễn trên, chúng tôi tiến hành kết hợp MeV với kháng thể đơn dòng Nimotuzumab nhằm mục đích cộng hợp tác dung điều trị ung thư theo cơ chế của hai liệu pháp trên để có thể đem lai hiệu quả tốt trong điêu trị ung thư biểu mô tể bào vảy đầu cổ. Kết quả nghiên cứu của chúng tôi cho thây hiệu quả gây hoại tử tế bào ung thư đầu cổ của sư kết hợp điều trị MeV+Nimotuzumab cao hơn đáng kể so với điều trị đơn với $\mathrm{MeV}$ hoặc Nimotuzumab in vitro.

\section{KẾT LUÂN}

Kết hợp $M e V$ và Nimotuzumab gây chết kiểu hoại tử đối với tế bào Hep2 nhiều hơn có ý nghĩa thổng kê so với điều trị đơn $\mathrm{MeV}$ hoặc Nimotuzumab và nhóm chứng.

\section{TÀI LIÊU THAM KHẢO}

1. Grandis JR T.D. (1993). Elevated levels of transforming growth factor alpha and epidermal growth factor receptor messenger RNA are early markers of carcinogenesis in head and neck cancer. Cancer Res., 53:3579-3584.

2. Alterio D., Marvaso G., Maffini F., et al. (2017). Role of EGFR as prognostic factor in head and neck cancer patients treated with surgery and postoperative radiotherapy: proposal of a new approach behind the EGFR overexpression. Med Oncol., 34(6): 107.

3. Sundaram S V.B., Sridharan $\mathbf{N}$ and Poojar K. (2015). Nimotuzumab with induction chemotherapy and chemo radiation in patients with advanced head and neck cancer. J Cancer., Ther 6:146 - 152.

4. Nguyễn Thị Thái Hòa (2015). Đánh giá kết quả điều trị kết hợp kháng thể đơn dòng Nimotuzumab - hóa xạ trị ung thư biểu mô vảy vưng đầu cổ giai đoạn lan tràn tại vùng, Luận án tiến sĩ y học, Trường Đại học Y Hà Nội.

5. Galanis E., Atherton P.J., Maurer M.J., et al. (2015). Oncolytic measles virus expressing the sodium iodide symporter to treat drug-resistant ovarian cancer. Cancer Res., 75(1):22-30.

6. Russell S.J., Federspiel M.J., Peng K.W., et al. (2014). Remission of disseminated cancer after systemic oncolytic virotherapy. Mayo Clin Proc., 89(7):926-933.

7. Son H.A., Zhang L., Cuong B.K., et al. (2018). Combination of Vaccine-Strain Measles and Mumps Viruses Enhances Oncolytic Activity against Human Solid Malignancies. Cancer Invest., 36(2):106-117.

8. Galanis E., Hartmann L.C., Cliby W.A., et al. (2010). Phase I trial of intraperitoneal administration of an oncolytic measles virus strain engineered to express carcinoembryonic antigen for recurrent ovarian cancer. Cancer Res., 70(3):875-882.

\title{
KIẾN THỨC-THỰC HÀNH VỀ Y ĐỨC CỦA DIỀU DƯỠNG VIÊN BÊ̂NH VIỆN PHỔI TỈNH PHÚ THỌ NĂM 2019
}

\author{
Trần Như Nguyên ${ }^{1}$, Lê Anh Hải, Nguyễn Thị Hồng Hà ${ }^{2}$ \\ Phạm Bá Nhất, Đinh Ngọc S $\tilde{y}^{3}$
}

\section{TÓM TẮT}

Nghiên cứu tiến hành trên toàn bộ 40 điều dưỡng viên Bệnh viện Phổi tỉnh Phú Thọ năm 2019, nhằm mô tả thực trang kiến thức và thực hành về $Y$ đức của họ, kết quả cho thây: Về Kiến thức đạt mức tốt(các tiều chí ở mức 76,7-100\%) trong đó có những tiêu chí rất cao : $95 \%$ hiểu về sẵn sàng giúp đõ chia sẻ với đồng nghiệp; 97,5\% về bảo vệ danh dự đồng nghiệp, $90 \%$ về người bệnh được quyền biết về bệnh của mình,

\footnotetext{
${ }^{1}$ Trường Đại Họ Y Hà Nôi

²Bênh viện Phổi tỉnh Phú Thọ

${ }^{3}$ Trường Đại hoc Thành Đông Hải Dương

Chịu trách nhiệm chính: Phạm Bá Nhất

Email: banhat001@gmail.com

Ngày nhận bài: 15/11/2020

Ngày phản biên khoa hoc: $5 / 12 / 2020$

Ngày duyệt bài: 16/12/2020
}

được giải thích, được lựa chọn kỹ thuâtt chăm sóc. Tuy nhiên còn $10 \%$ cho rằng bệnh nhân không được quyền chọn điều dưỡng viên chăm sóc cho mình; 3,3\% không biết nghề điêuu dưỡng có phù hợp với bản thân không. Về Thực hành đạt mức khá tốt (các tiêu chí ở mức $50-100 \%$ ) trong đó có những tiêu chí rất cao: $97,5 \%$ thực hện tốt việc chiu trách nhiêm về hành vi chuyên môn; $100 \%$ trung thực trong sử dụng thuốc và vật tư tiêu hao. Nhưng còn đến $50 \%$ điều dưỡng viên không hỏi thêm người bệnh các bệnh liên quan; chỉ $40 \%$ có giới thiệu tên và nều lý do tiếp xúc, chỉ $30 \%$ có chú ý tới tâm trạng người nhà người bệnh và $20 \%$ không hỏi lý do người bệnh đến khám

Tư khóa: Kiến thức, thực hành, y đức

\section{SUMMARY \\ KNOWLEDGE, PRACTICE ON MEDICAL ETHICS OF NURSES FROM PHU THO \\ HOSPITAL OF LUNG DISEASE IN 2019}


The cross-sectional study conducted on all 40 nurses from Phu Tho Hospital of Lung Disease in 2019, objecties to describe the current state of their knowledge and practice on Medical Ethics, the results showed: Knowledge: good level (the criteria is at $76,7-100 \%$ ), of which there are very high ones: $95 \%$ understand the willingness to help share with colleagues; $97.5 \%$ about protecting the honor of colleagues, $90 \%$ about patients have the right to know about their diseases, to be explained to, and to choose a care technique. However, $10 \%$ believe that patients cannot choose a nurse to care for them; 3,3\% do not know if nursing is suitable for themselves. Practice: rather good level (the criteria is at $50-100 \%$ ), of which there are very high criteria: $97,5 \%$ is good at taking responsibility for professional behavior; $100 \%$ honest in use of medicines and consumables. However, up to $50 \%$ of nurses did not ask more patients about related diseases; Only $40 \%$ introduced their name and the reason of contact, only $30 \%$ paid attention to the patient's family's mood and $20 \%$ did not ask the reason for the visit.

Key words: Knowledge, practice, medical ethics.

\section{I. ĐĂT VẤN ĐỀ}

Y đức là những tiêu chuẩn, nguyên tắc được dư luận xã hội thừa nhân, y đức quy định hành vi và mối quan hệ giữa thây thuốc với người bệnh (NB) cũng như đồng nghiệp. $Y$ đức là phẩm chất tốt đẹp của người làm công tác y tế, được biểu hiện ở tinh thần trách nhiệm cao, tận tuy. phục vụ, hết lòng yêu thương chăm sóc người bệnh [1],[2],[3],[4], Việc nâng cao kiến thức và thực hành y đức của nhân viên y tế là cần thiết. Điều dưỡng viên (ĐDV) có vai trò quan trọng trong cung cấp dịch vụ chăm sóc sức khỏe chất lương cao, duy trì và cải thiên sức khỏe bênh nhân và cộng đồng. Hành vi đạo đức của điều dưỡng viên đối với bệnh nhân (BN) ảnh hưởng manh mẽ đến sự cải thiên sức khỏe của bênh nhân, vì vâyy với điều dưỡng viên không chỉ nẩng cao chuyên môn mà còn phải trau dồi về kiến thức, thực hành y đức để hướng đến hiệu quả trong công tác chăm sóc và điêu trị [5], [6]. Bệnh viện Phổi tỉnh Phú Thọ là bệnh viện chuyên điều trị bệnh nhân lao và bênh phổi cho người dân toàn tỉnh. Lao là bệnh dễ lây truyền, dễ dẫn đến sư e ngai, kì thi và phân biêt đối xữ với $B N$ nên kiến thức-thực hành y đức ở điều dưỡng viên càng quan trọng. Từ tình hình trên đề tài được tiến hành nhẳm những mục tiêu sau:

1. Mô tả thực trạng kiến thức y đức của điều dưỡng viên Bềnh viện Phổi Phú Thọ năm 2019.

2. Mô tả thực trạng thực hành y đức của điều dưỡng viên Bềnh viện Phổi Phú Tho

II. ĐỐI TƯợNG VÀ PHƯƠNG PHÁP NGHIÊN CỨU

2.1.Địa điểm, thời gian: Bệnh viện Phổi tỉnh Phú Thọ. năm 2019
2.2. Đối tượng: Khối điều dưỡng viên của Bệnh viện Phổi tỉnh Phú Thọ

2.3. Phương pháp: Thiết kế nghiên cứu: Mô tả cắt ngang. Cỡ mâu-chon mẫu: toàn bô 40 điều dưỡng viên. Kiến thức và thực hành về $Y$ đức được xây dựng theo [5],[6], công cụ thu thập số liệu được thử nghiệm và hoàn chỉnh. Kiển thức được phỏng vấn và thực hành được quan sát. Sai số được khống chế bằng chuẩn hóa các công cụ và kỹ̃ thuật thu thập số liệu. Số liêu được nhập bằng EPIDATA 3.0, phân tích bằng SPSS 20.0 với các test thống kê mô tả.

2.4. Đạo đức nghiên cứu: Không vi phạm các tiêu chí của đạo đức nghiên cứu. Tuân thủ các quy định về đạo đức nghiên cứu của thông tư 45/2017/TT-BYT [7]

\section{KẾT QUẢ NGHIÊN CỨU}

3.1. Thông tin chung về đối tượng tham gia nghiên cứu

- Đặc điểm ĐDV tại bệnh viện $(n=40)$

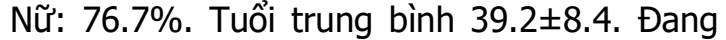
có vợ, chồng: $98.3 \%$. Trình độ đại học: $26.7 \%$, trên đại học: $5 \%$. Thâm niên công tác từ 5-10 năm: $36.7 \%$.

3.2. Kiến thức y đức của ĐDV tại Bệnh viện Phổi Phú Thọ

- Kiến thức y đức về quan hê với đông nghiêp

Bảng 1. Môí quan hệ đồng nghiệp của $\oplus D V(n=40)$

\begin{tabular}{|c|c|c|c|c|}
\hline \multicolumn{3}{|c|}{\begin{tabular}{|l|l|l} 
Phản ánh của đồng nghiệp $S L$ \\
\end{tabular}} & \multicolumn{2}{|c|}{$\%$} \\
\hline \multirow{3}{*}{$\begin{array}{c}\text { Tôn trọng bảo vệ } \\
\text { danh dự đồng } \\
\text { nghiệp }\end{array}$} & Rất tốt & 3 & 7.5 & \multirow{2}{*}{97.5} \\
\hline & Tốt & 36 & 90 & \\
\hline & $\begin{array}{l}\text { Bình } \\
\text { thường }\end{array}$ & 1 & 2.5 & \\
\hline \multirow{3}{*}{$\begin{array}{c}\text { Sẵn sàng giúp đỡ, } \\
\text { chia sẻ kinh nghiệm } \\
\text { với đồng nghiệp }\end{array}$} & Rất tốt & 3 & 7.5 & \multirow{2}{*}{95} \\
\hline & Tốt & 35 & 87.5 & \\
\hline & $\begin{array}{l}\text { Bình } \\
\text { thường }\end{array}$ & 2 & 5 & \\
\hline \multirow{4}{*}{$\begin{array}{l}\text { Không trốn tránh } \\
\text { đùn đấy trách nhiệm }\end{array}$} & Rất tốt & 3 & 7.5 & \multirow[t]{2}{*}{90} \\
\hline & Tốt & 33 & & \\
\hline & $\begin{array}{l}\text { BInn } \\
\text { thường }\end{array}$ & 4 & 10 & \\
\hline & Không & 40 & 100 & \\
\hline \multirow{2}{*}{$\begin{array}{l}\text { Phản ánh sai sự } \\
\text { thật, làm giảm uyy } \\
\text { tín đồng nghiệp }\end{array}$} & Có & 0 & n & \\
\hline & Không & 40 & 100 & \\
\hline
\end{tabular}

100\% ĐDV không phản ánh sai sự thật làm giảm uy tín đồng nghiệp, 97,5\% ĐDV tôn trọng bảo vê danh dự đồng nghiệp mức tốt/ rất tốt;

Bảng 2. Sự hài lòng về môi quan hệ với đồng nghiệp $(n=40)$

\begin{tabular}{|c|c|c|}
\hline Hài lò̀ng & SL & \% \\
\hline Có & 39 & 97.5 \\
\hline Không & 1 & 2.5 \\
\hline
\end{tabular}


97,5\% hài lòng về mối quan hệ với đồng nghiệp

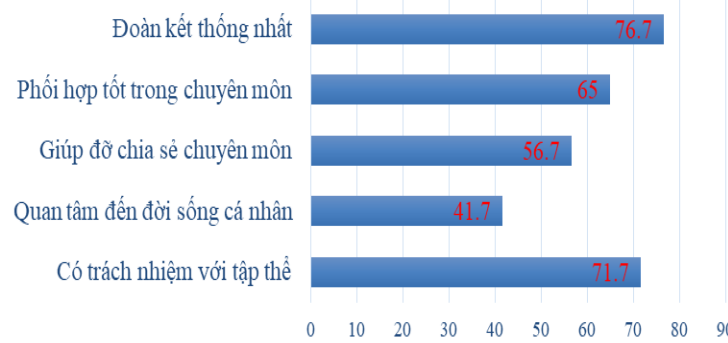

Biểu đồ 1. Kiến thức trong mối quan hệ với đồng nghiêp $(n=40)$

$76.7 \%$ ĐDV cho rằng quan hệ đồng nghiệp phải đoàn kết thống nhất, $71.7 \%$ cho rằng phải có trách nhiệm với tập thể. $65 \%$ cho rằng phải phối hợp tốt trong chuyên môn,

- Kiến thức về sự cân thiết về y đức

Bảng 3. Sự cần thiêt $y$ đức ở $Đ D V$ $(n=40)$

\begin{tabular}{|c|c|c|c|}
\hline \multicolumn{2}{|c|}{ Nhận thức } & SL & $\%$ \\
\hline $\begin{array}{c}\text { Nghe về } \\
\text { chuẩn đạo }\end{array}$ & $\begin{array}{c}\text { Nghe nói, chưa } \\
\text { đọc }\end{array}$ & 01 & 2.5 \\
\cline { 2 - 4 } $\begin{array}{c}\text { đức nghề } \\
\text { nghiệp }\end{array}$ & Có, lồng ghép & 31 & 77.5 \\
\cline { 2 - 4 } & Học môn riêng & 08 & 20 \\
\hline $\begin{array}{c}\text { Sự cần } \\
\text { thiết về y }\end{array}$ & Rất cần thiết & 27 & 67.5 \\
\cline { 2 - 4 } đức ĐDV & Cần thiết & 13 & 32.5 \\
\cline { 2 - 4 } & Không cần thiết & 0 & 0 \\
\hline
\end{tabular}

$100 \%$ đối tượng cho rằng $\mathrm{y}$ đức ĐDV là cần thiết/ rất cần thiết (32.5 và 67.5\%); 77,5\% ĐDV được nghe về chuẩn đạo đức nghề nghiệp thông qua hoạt động lồng ghép

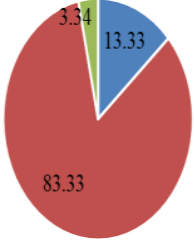

$$
\begin{aligned}
& \text { - Rất phù hợp } \\
& \text { - Phù hợp } \\
& \text { - Bình thường, không biết }
\end{aligned}
$$

Biểu đồ 2. Mức độ thấy phù hợp với nghề nghiệp của $Đ D V(n=40)$

$96,6 \%$ ĐDV thấy phù hợp/rất phù hợp với nghề nghiệp $(83,3 / 13,3 \%)$

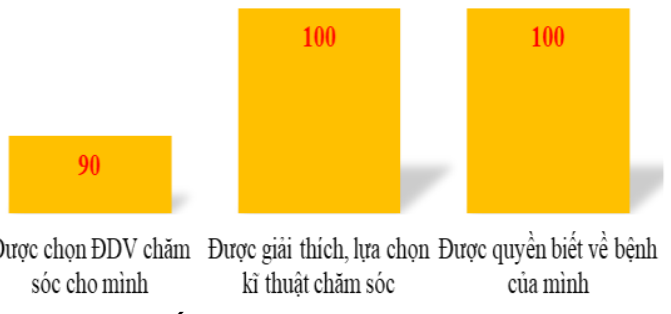

Biểu đồ 3. Ý kiến của $Đ D V$ về quyền của $N B$ $(n=40)$
$100 \%$ ĐDV cho rằng NB được quyền biết về bệnh của mình và được giải thích, lựa chọn kĩ thuật chăm sóc; $90 \%$ cho rằng NB được quyền chọn ĐDV chăm sóc cho mình.

3.3. Thức trang thức hành y đức của điêuu dưỡng viên BV Phổi tỉnh Phú Thọ

- Thực hành y đức trong chuyên môn của ĐDV

Bảng 4. Thực hiên sự phân công về

\begin{tabular}{|c|c|c|c|c|}
\hline \multirow{3}{*}{$\begin{array}{l}\text { Thực hành tốt } \\
\text { các quy trình kĩ } \\
\text { thuật }\end{array}$} & & & & \multirow[b]{2}{*}{87.5} \\
\hline & $\begin{array}{l}\text { Rất tốt } \\
\text { Tốt }\end{array}$ & $\begin{array}{c}3 \\
32\end{array}$ & $\begin{array}{c}7.5 \\
80\end{array}$ & \\
\hline & $\begin{array}{l}\text { Bình } \\
\text { thường }\end{array}$ & 5 & 12.5 & \\
\hline \multirow{3}{*}{$\begin{array}{c}\text { Chịu trách nhiềm } \\
\text { về hành vi } \\
\text { chuyên môn }\end{array}$} & Rất tốt & 3 & 7.5 & \multirow{2}{*}{97.5} \\
\hline & Tốt & 36 & 90 & \\
\hline & $\begin{array}{l}\text { Bình } \\
\text { thường }\end{array}$ & 1 & 2.5 & \\
\hline \multirow{3}{*}{$\begin{array}{l}\text { Can thiệp kịp } \\
\text { thời, báo cho phụ } \\
\text { trách khi phát } \\
\text { hiện làm sai }\end{array}$} & Rất tốt & 3 & 7.5 & \multirow{2}{*}{92.5} \\
\hline & Tốt & 34 & 85 & \\
\hline & $\begin{array}{l}\text { Binh } \\
\text { thường }\end{array}$ & 3 & 7.5 & \\
\hline \multirow{2}{*}{$\begin{array}{l}\text { Thực hiện tốt } \\
\text { đây đủ ca trực }\end{array}$} & Có & 38 & 95 & \\
\hline & Không & 2 & 5 & \\
\hline \multirow{2}{*}{$\begin{array}{l}\text { Trung thực trong } \\
\text { sứ dụng thuốc và } \\
\text { vật tư tiêu hao }\end{array}$} & Rất tốt & 3 & 7.5 & \multirow[b]{2}{*}{100} \\
\hline & Tốt & 37 & 92.5 & \\
\hline \multirow{3}{*}{$\begin{array}{l}\text { Trung thực trong } \\
\text { chuyên môn }\end{array}$} & Rất tốt & 3 & 7.5 & \multirow{3}{*}{97.5} \\
\hline & Tốt & 36 & 90 & \\
\hline & $\begin{array}{l}\text { Bình } \\
\text { thường }\end{array}$ & 1 & 2.5 & \\
\hline \multirow{2}{*}{$\begin{array}{l}\text { Trung thực trong } \\
\text { việc ghi chép }\end{array}$} & Rất tốt & 3 & 7.5 & \multirow{2}{*}{100} \\
\hline & Tốt & 37 & 92.5 & \\
\hline \multirow{3}{*}{$\begin{array}{c}\text { Có báo cáo công } \\
\text { á́c thường xuyên } \\
\text { với lãnh đạo }\end{array}$} & Rất tốt & 2 & 5 & \multirow{3}{*}{60} \\
\hline & $\begin{array}{l}\text { Tốt } \\
\text { Bình }\end{array}$ & 22 & 55 & \\
\hline & $\begin{array}{c}\text { Bimnn } \\
\text { thường }\end{array}$ & 16 & 40 & \\
\hline $\begin{array}{c}\text { Có lối sống lành } \\
\text { mạnh }\end{array}$ & Rất tốt & 3 & 7.5 & 100 \\
\hline \multirow{4}{*}{$\begin{array}{l}\text { Thường xuyên } \\
\text { rèn luyện kĩ năng } \\
\text { giao tiếp với } \\
\text { khách hàng }\end{array}$} & \begin{tabular}{|l} 
Iot \\
Rất tốt
\end{tabular} & $\frac{31}{3}$ & $\begin{array}{l}92.5 \\
7.5\end{array}$ & \multirow[b]{2}{*}{82.5} \\
\hline & Tốt & 30 & 75 & \\
\hline & $\begin{array}{l}\text { Bình } \\
\text { thường }\end{array}$ & 6 & 15 & \\
\hline & Kém & 1 & 2.5 & \\
\hline
\end{tabular}
chuyên môn của ĐDV $(n=40)$

\begin{tabular}{|l|l|l|l|l|}
\hline Các tiêu chuấn & Mức độ & SL & $\%$ & Tống \\
\hline
\end{tabular}

$100 \%$ đat "trung thực trong viêc sư dung thuốc và vật tư tiêu hao, "trung thực trong việc ghi chép" và "có lối sống lành mạn" $82.5 \%$ thường xuyên rèn luyện kỹ năng giao tiếp với khách hàng (mức tốt/rất tốt).

- Thực hành chăm sóc NB của ĐDV qua quan sát

Bảng 5. Cách giới thiệu, chào hỏi NB ở $\oplus D V(n=40)$ 


\begin{tabular}{|c|c|c|c|}
\hline \multicolumn{2}{|c|}{ Tiêu chí } & SL & \% \\
\hline \multirow{2}{*}{$\begin{array}{c}\text { Chào hỏi NB, } \\
\text { mời ngồi }\end{array}$} & Có & 39 & 97.5 \\
\cline { 2 - 4 } & Không & 1 & 2.5 \\
\hline $\begin{array}{c}\text { Giới thiệu tên, nêu lí do } \\
\text { tiếp xúc }\end{array}$ & Có & 16 & 40 \\
\cline { 2 - 4 } & Không & 24 & 60 \\
\hline
\end{tabular}

$97.5 \%$. ĐDV có chào hỏi NB, mời ngồi. 40\% giới thiệu tên và nêu lí do tiếp xúc

Bảng 6. Hỏi lí do BN đến khám ở ĐDV $(n=40)$

\begin{tabular}{|c|c|c|c|}
\hline \multicolumn{2}{|l|}{ Tiêu chí } & SL & $\%$ \\
\hline \multirow{2}{*}{$\begin{array}{c}\text { Hỏi lí do bệnh nhân } \\
\text { đến khám }\end{array}$} & Có & 32 & 80 \\
\hline & Không & 8 & 20 \\
\hline \multirow{2}{*}{$\begin{array}{l}\text { Chú ý đên tâm } \\
\text { trạng người nhà NB }\end{array}$} & Có & 12 & 30 \\
\hline & Không & 28 & 70 \\
\hline
\end{tabular}

Bảng 7. Hỏi, giải thích và hướng dẫn làm XN cúa ĐDV $(n=40)$

\begin{tabular}{|c|c|c|c|}
\hline \multicolumn{2}{|l|}{ Tiêu chí } & $\mathbf{S L}$ & $\%$ \\
\hline \multirow{2}{*}{$\begin{array}{c}\text { Hỏi thêm các bệnh } \\
\text { liên quan }\end{array}$} & Có & 20 & 50 \\
\hline & Không & 20 & 50 \\
\hline \multirow{2}{*}{$\begin{array}{c}\text { Giải thích về bệnh } \\
\text { cho người bệnh và } \\
\text { NNNB }\end{array}$} & Có & 28 & 70 \\
\hline & Không & 12 & 30 \\
\hline \multirow{2}{*}{$\begin{array}{c}\text { Hướng dân người } \\
\text { nhà, người bệnh đi } \\
\text { làm xét nghiệm }\end{array}$} & Có & 40 & 100 \\
\hline & Không & 0 & 0 \\
\hline
\end{tabular}

100\% ĐDV có hướng dấn người nhà và NB đi làm xét nghiệm.70\%có giải thích về bênh cho người nhà NB và NB; $50 \%$, ĐDV có hỏi thêm các bênh liên quan.

Bảng 8. Hướng dẫn cách chăm sóc và sử dụng thuốc của ĐDV $(n=40)$

\begin{tabular}{|c|c|c|c|}
\hline \multicolumn{2}{|c|}{ Tiêu chí } & SL & $\%$ \\
\hline $\begin{array}{c}\text { Giải thích các phương } \\
\text { pháp chăm sóc }\end{array}$ & Có & 32 & 80 \\
\cline { 2 - 4 } & Không & 08 & 20 \\
\hline Hướng dâ̂n sứ dụng & Có & 40 & 100 \\
\cline { 2 - 4 } thuốc & Không & 0 & 0 \\
\hline
\end{tabular}

$80 \%$ có giải thích phướng pháp chăm sóc và $100 \%$ có hướng dẫn sử dụng thuốc

Bảng 9. Giải thích cách phòng bênh và nơi đến tiếp của ĐDV $(n=40)$

\begin{tabular}{|c|c|c|c|}
\hline \multicolumn{2}{|c|}{ Tiêu chí } & SL & \% \\
\hline Giải thích cách phòng & Có & 26 & 65 \\
\cline { 2 - 4 } bệnh & Không & 14 & 35 \\
\hline Hướng dấn đến phòng & Có & 35 & 92.5 \\
\cline { 2 - 4 } khám tiếp theo & Không & 5 & 7.5 \\
\hline
\end{tabular}

$92.5 \%$. ĐDV có hướng dấn đến phòng khám tiếp theo.65\% ĐDV có giải thích cách phòng bệnh cho người nhà và NB

\section{BÀN LUÂ̂N}

4.1. Thực trạng kiến thức $y$ đức của ĐDV

Trong mối quan hệ với đồng nghiệp, hầu hết ĐDV có nhận thức và hiểu đúng về tôn trọng bảo vệ danh dự đồng nghiệp (97,5\%); sẵn sàng giúp đỡ chia sẻ kinh nghiệm với đồng nghiệp (95\%); không trốn tránh đùn đẩy trách nhiệm (90\%). 100\% ĐDV không có phản ánh sai sự thật làm giảm uy tín đồng nghiệp. Trong công việc điều dưỡng viên luôn thực hiện ba chức năng nghề nghiệp đó là chức năng phụ thuộc, chức năng độc lập và chức năng phối hợp để hoàn thành nhiệm vụ. Chức năng phối hợp thể hiện sự liên hệ chặt chẽ giữa điều dưỡng viên với các nhân viên khác nhằm đem lại sự chăm sóc người bệnh (NB) được đầy đủ. Sự hài lòng trong quan hệ với đồng nghiệp là yếu tố quan trọng thúc đẩy cho mối quan hệ giữa các ĐDV được tốt hơn, và qua đó cũng sẽ đạt được sự giúp đõ nhau đạt kết quả tốt trong công việc. Kết quả nghiên cứu cho thấy tỷ lệ hài lòng trong quan hệ đồng nghiệp rất cao $97.5 \%$ và chỉ có duy nhất 1 đối tượng là không hài lòng $(2,5 \%)$. Kết quả này cao hơn nghiên cứu của một số tác giả [8][9]. Sự hài lòng về nghề nghiệp của ĐDV: bao gồm: hài lòng về ước muốn nghề nghiệp; về mức độ phù hợp nghề nghiệp với khả nằng của bản thân, nghiên cứu cho thấy $96,6 \%$ đối tượng phù hợp nghề nghiệp. Số ĐDV có nhận thức rất tốt về quyền của NB đến $100 \%$ (NB được quyền biết về bệnh của mình và được giải thích, lựa chọn kĩ thuật chăm sóc). $90 \%$ cho rằng $\mathrm{NB}$ được chọn ĐDV chăm sóc cho mình. Kết quả này cao hơn nghiên cứu của một số tác giả [8].

4.2. Thực trang thực hành $y$ đức của ĐDV. Thực hành trong phân công chuyên môn ở ĐDVcó vai trò quyết định đến chất lượng chăm sóc NB của ĐDV. Kết quả nghiên cứu cho thấy đa số ĐDV thực hiên khá tốt tiêu chuẩn thực hành:các chỉ số đều đat từ $66,7 \%$ trở lên. Trong đó có những chỉ số đạt rất cao: $98.3 \%$ ĐDV thực hiên tốt tiêu chí chịu trách nhiệm về hành vi chuyên môn và trung thực về chuyên môn; 100\% ĐDV đạt tiêu chí trung thực trong việc sử dụng thuốc, vật tư tiêu hao và trung thực trong ghi chép; 92,5\% ĐDV thực hiện tốt tiêu chí can thiệp kịp thời, báo cho phụ trách khi phát hiện làm sai. Tiêu chí thường xuyên rèn luyên kĩ năng giao tiếp với khách hàng mức tốt/rất tốt đạt $82,5 \%$. Là những người thường xuyên tiếp xúc với khách hàng, ĐDV hiện hoàn nhiệm vụ thăm khám, chăm sóc mà ít hỏi han, giao tiếp với NB, đặc biệt là những bệnh nhân lao. Kết quả trên cùng xu hướng với nghiên cứu khác [8]. Cũng qua quan sát: cách giới thiệu, chào hỏi NB ở ĐDV, hầu hết ĐDV đều thực hiến chào hỏi NB và mời ngồi $(97.5 \%)$, nhưng tỷ lệ ĐDV giới thiệu tên, nêu lí do tiếp xúc thấp (chỉ $40 \%$ ). Về hỏi lí 
do BN đến khám, $80 \%$ ĐDV có hỏi lí do BN đến khám và vẫn còn $20 \%$ ĐDV không hỏi, tỷ lệ ĐDV chú ý đến tâm trạng người nhà cũng thấp (chỉ $30 \%$ ). Về hỏi bệnh và hướng dẫn tận tình của ĐDV, tỷ lê ĐDV hỏi bênh, hướng dẫn tân tình đat mức khá tốt. ĐDV hỏi thêm các bệnh có liên quan, $80 \%$ ĐDV giải thích về bệnh cho người nhà và $\mathrm{NB}$ và $100 \%$ ĐDV hướng dẫn người nhà và NB đi làm xét nghiệm. $100 \%$ ĐDV có hướng dẫn sử dụng thuốc cho NB. 53.3\%. ĐDV có giải thích các phương pháp chăm sóc. $65 \%$ ĐDV giải thích cách phòng bệnh cho người nhà và NB. 92,5\% ĐDV có hướng dẫn đến phòng khám tiếp theo. So với nghiên cứu khác, các tiêu chí này có cao hơn [8].

\section{KẾT LUÂN}

- Về Kiến thức đat mức tốt (các tiêu chí đat mức 76,7-100\%) trong đó có những tiêu chí rất cao: $95 \%$ hiểu về sẵn sàng giúp đõ chia sẻ với đồng nghiệp; $97,5 \%$ về bảo vệ danh dự đồng nghiệp, $90 \%$ về người bệnh được quyền biết về bệnh của mình, được giải thích, được lựa chọn kỹ் thuật chăm sóc. Tuy nhiên còn $10 \%$ cho rằng bệnh nhân không được quyền chọn điều dưỡng viên chăm sóc cho mình; 3,3\% không biết nghề điều dưỡng có phù hợp với bản thân không.

- Về Thực hành đạt mức khá tốt (các tiêu chí đat mức 50-100\%) trong đó có những tiêu chí rất cao: $97,5 \%$ thực hiện tốt việc chịu trách nhiệm về hành vi chuyên môn; $100 \%$ trung thực trong sử dụng thuốc và vật tư tiêu hao. Nhưng còn đến $50 \%$ điều dưỡng viên không hỏi thêm người bệnh các bệnh liên quan; chỉ $40 \%$ có giới thiệu tên và nêu lý do tiếp xúc, chỉ $30 \%$ có chú ý tới tâm trạng người nhà người bệnh và $20 \%$ không hỏi lý do người bệnh đến khám

\section{TÀI LIẸU THAM KHẢO}

1. European Nursing Community (2008). Code of Ethics and Conduct for European. Nursing. Protecting the Public and Ensuring patient safety,. P 1-9

2. Australian College of Nursing (2008), Code of Ethics for Nurses in Australia, Nursing and Midwifery Board of Australia, The Australian College of Nursing and The Australia Nursing Federation, ISBN: 978-0-9775108-7-0, 2008.

3. Japanese Nursing Association (2003), The code of ethics for nurses, Full text PDF document. 2003: p. 1-7.

4. College and Association of Registered Nurses of Alberta (CARNA), Nursing Practice Standard, Edmonton, AB T5M 4A6, 2005: p. 1-32.

5. Bộ Y tế (2012). Chuấn năng lực cớ bản của điều dưỡng Việt Nam. Ban hành kèm theo quyết định số: 1352/QĐ-BYT. Tr 1-14

6. Hội Điêuu dưỡng Viêt Nam, Quyết đinh số 20/QĐ-HĐD ngày 10/9/2012 vế chuẩn đạo đức nghể nghiệp của điều dưỡng viên, Hội nghị phát triển nguồn nhân lực điêu dưỡng Việt Nam, 2012: p. 42-49.

7. Bộ Y tế (2017) Quy định việc thành lập, chức nẳng, nhiệm vụ, quyên hạn của Hội đồng đạo đức trong nghiên cứu y sinh hoc. Thông tư 45/2017/TT-BYT (ngày 16/11/2017)

8. Đố Manh Hùng, (2014), Nghiên cứu thực trang nhận thức và thực hành y đức của điều dưỡng viên tại Bệnh viên Nhi Trung ương và kết quả một số biên pháp can thiêpp. Luận văn ThS. Đại học $Y$ Dược Thái Bình.

\title{
ĐÁNH GIÁ HIẾU QUẢ VIRUS VACCINE SỞI VÀ NIMOTUZUMAB GÂY BÊNH CHẾT TẾ BÀO UNG THƯ THEO CON ĐƯỜNG APOPTOSIS GIAI ĐOẠN MUỘN
}

\author{
Hồ Anh Sơn'1, Lê Mạnh Cường², Nguyễn Văn Chuyên'1
}

\section{TÓM TẮT}

Mục tiêu: Đánh giá hiệu quả virus vaccin sởi (MeV) và Nimotuzumab gây chết tế bào ung thư theo con đường apoptosis giai đoạn muộn. Đối tượng và phương pháp: Sử dụng MeV và Nimotuzumab gây chết tế bào ung thư Hep2. Tế bào Hep2 tiếp xúc MeV

${ }^{1}$ Học viện Quân y

²Bệnh viện YHCT Trung ương

Chiu trách nhiệm chính: Hồ Anh Sơn

Email: hoanhsonhp@gmail.com

Ngày nhận bài: 11/11//2020

Ngày phản biên khoa học: 3/12/2020

Ngày duyệt bài: 17/12/2020 và Nimotuzumab được thu thâp ở thời điểm 48 giờ, 72 giờ, 96 giờ để đánh giá bằng kỹ thuật flow cytometry. Kết quả: Tỉ lế tế bào chết theo chương trình giai đoạn muộn ở các nhóm điều trị nhiều hớn có nghĩa thổng kê so với nhóm chứng, thời điểm 96h, kết hợp $\mathrm{MeV}$ và Nimotuzumab gây chết tế bào ung thư apoptosis giai đoạn muộn nhiêu hơn so với dùng đơn. Kết luận: Kết hợp virus vaccine sởi và Nimotuzumab có tác dụng gây chết tế bào Hep2 theo chương trình giai đoạn muộn nhiều hơn dùng đơn virus vaccine sởi hoặc Nimotuzumab.

Tư khóa: Ung thư đâu cổ, virus vaccine sởi, Nimotuzumab, chết theo chương trình

SUMMARY 